\title{
Enantioselective total synthesis of (-)-epoxyquinols $A$ and $B$. Novel, convenient access to chiral epoxyquinone building blocks through enzymatic desymmetrization
}

\author{
Goverdhan Mehta* and Kabirul Islam \\ Department of Organic Chemistry, Indian Institute of Science, Bangalore 560 012, India
}

\begin{abstract}
Following our recent total synthesis of the biologically potent natural products epoxyquinols A and B in racemic form, we have now accomplished the total synthesis of the (-)-epoxyquinols $\mathrm{A}$ and $\mathrm{B}$, anti-podes of the angiogenesis inhibiting natural products, through a protocol that involves enzymatic desymmetrization of a versatile epoxyquinone derivative, readily available from the Diels-Alder adduct of cyclopentadiene and $p$-benzoquinone.
\end{abstract}

Several polyketide derived natural products, bearing the epoxyquinone moiety $\mathbf{1}$ as the core structure, have been encountered in nature from diverse sources in recent years. ${ }^{1}$ Typical examples of such natural products are eupenoxide $2{ }^{1 \mathrm{a}}$ cycloepoxydon $3^{1 \mathrm{~b}}$ and $\mathrm{ECH} 4^{\text {lc }}$ among others, and many of them exhibit promising, wide ranging biological activity profiles. Quite naturally, epoxyquinone natural products have evoked considerable attention from the synthetic community over the past few years. ${ }^{2}$ In our view, central to the synthetic approach to these natural products is a short, viable access route to the core structure $\mathbf{1}$ with adequately functionalized side arms. In this context, we have<smiles>[R]P[C@@H]1C(C)=C(C)C(=O)[C@@H]2O[C@H]21</smiles><smiles>CCCCC/C=C/C1=C(CO)[C@@H](O)[C@H]2OC2[C@H]1O</smiles><smiles>CCC[C@H]1OCC2=C([C@H](O)[C@@H]3O[C@H]3C2=O)[C@H]1O</smiles><smiles>C/C=C/C1=C(CO)[C@@H](O)[C@H]2OC2C1=O</smiles>

\footnotetext{
* Corresponding author. Tel.: +91802932850; fax: +91803600936; e-mail: gm@orgchem.iisc.ernet.in
}

recently disclosed a convenient three step access to the epoxyquinone building block 5 (cf. 1) $)^{3}$ from the readily available Diels-Alder adduct $\mathbf{6}$ of cyclopentadiene and $p$-benzoquinone, Scheme 1. Recognizing the inherent versatility of 5 in the synthesis of epoxyquinone natural products, it was considered imperative to access its derivatives in enantiomerically pure form to harness fully its potential. The symmetrical nature of $\mathbf{5}$ lends itself amenable to the enzyme mediated 'meso trick'. Indeed, the enzymatic desymmetrization of $\mathbf{5}$ has now been achieved and in this letter, we demonstrate the preparation of enantiomerically enriched derivatives of 5 and their utility in the total synthesis of (-)-epoxyquinols $\mathrm{A}$ and $\mathrm{B} .{ }^{4}$

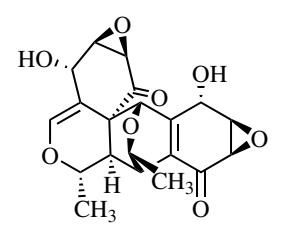

(+) - Epoxyquinol A

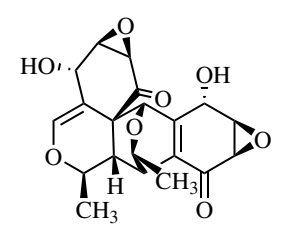

(+) - Epoxyquinol B
After considerable experimentation with several lipases and reaction conditions, we were able to devise a simple, reproducible protocol for the enzymatic desymmetrization of 5 through transesterification, in a biphasic medium employing lipase PS 30 (Amano) immobilized on Celite, to furnish monoacetate $(+)-7 \quad(\sim 99 \%$ ee $)$, 


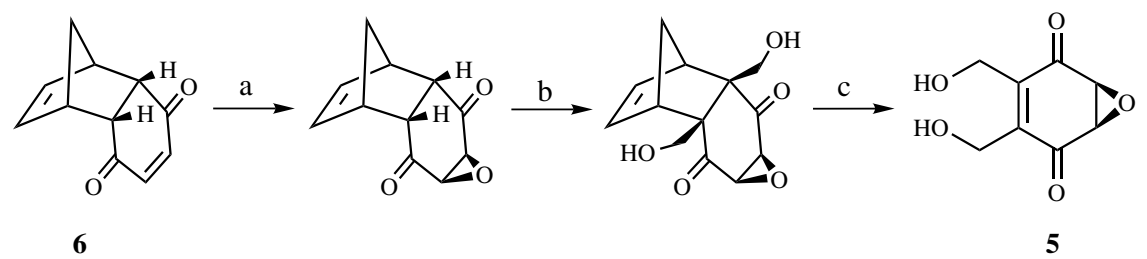

Scheme 1. Reagents and conditions: (a) $30 \% \mathrm{H}_{2} \mathrm{O}_{2}, 10 \% \mathrm{Na}_{2} \mathrm{CO}_{3}$, acetone, $0{ }^{\circ} \mathrm{C}, 95 \%$; (b) $\mathrm{DBU}, 40 \%$ formalin, THF, $92 \%$; (c) diphenylether, $240{ }^{\circ} \mathrm{C}$, $90 \%$.

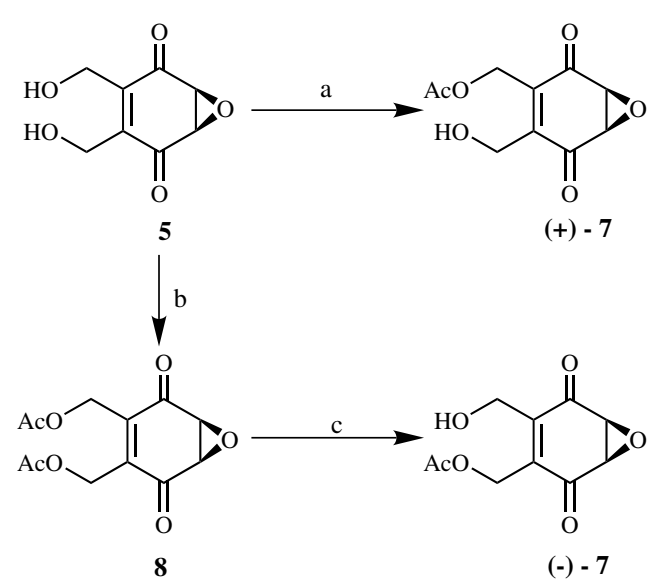

Scheme 2. Reagents and conditions: (a) Lipase PS 30 (Amano), vinyl acetate, $t$-butylmethylether, $0{ }^{\circ} \mathrm{C}, 6 \mathrm{~h}, 82 \%$; (b) $\mathrm{Ac}_{2} \mathrm{O}$, pyridine, DMAP, DCM, $0{ }^{\circ} \mathrm{C}, 75 \%$; (c) C. rugosa lipase, distd water, phosphate buffer, $\mathrm{rt}$ $86 \%$.

Scheme $2 .{ }^{5}$ The absolute configuration of (+)-7 followed from its conversion to the natural products $(-)$-cycloepoxydon $^{2 \mathrm{i}}$ and (-)-epoxyquinols $\mathrm{A}$ and $\mathrm{B}$ (vide infra). Concurrently, meso-diol 5 was converted to the diacetate 8 and desymmetrization employing enzymatic hydrolysis with the same lipase PS 30 (Amano) gave (-)-7 $(\sim 86 \%$ ee) with modest enantioselectivity, Scheme 2. However, with the lipase from Candida rugosa (-)-7 was obtained from 8 in high enantiomeric purity $(\sim 99 \%$ ee $) .{ }^{5}$ The versatile building block 7 thus became readily accessible in both its enantiomerically enriched forms through enantiodivergency based protocols. We demonstrate here the utility of one of the enantiomers (+)-7 towards the enantioselective synthesis of epoxyquinone natural products (-)-epoxyquinol A 9 and (-)-epoxyquinol B 10.

Angiogenesis inhibition is emerging as a very promising protocol with therapeutic potential for a variety of disorders ranging from rheumatoid arthritis to cancer ${ }^{6}$ and several natural products are being explored as leads for clinical development. ${ }^{7}$ In this context, the report of the isolation of two pentaketide derived dimers (+)-epoxyquinol $\mathrm{A}$ and (+)-epoxyquinol $\mathrm{B}$ from a soil based unknown fungus in 2002, by Japanese scientists, has drawn the immediate attention of synthetic chemists as these unusual natural products exhibited impressive inhibition of angiogenesis. ${ }^{4}$ In a short span of one year, three total syntheses of these natural products have appeared in the literature. ${ }^{3,8}$ Two of these synthetic accomplishments by the groups of Hayashi ${ }^{8 \mathrm{a}}$ and Porco $^{8 \mathrm{~b}}$ are enantioselective and have led to the natural enantiomers (+)-epoxyquinol A and (+)-epoxyquinol B. On the other hand, our group has reported a synthesis of racemic epoxyquinols $\mathrm{A}$ and $\mathrm{B} .{ }^{3}$ In addition, Hayashi and co-workers have delineated a practical approach to both the enantiomers of epoxyquinols $\mathrm{A}$ and $\mathrm{B}$ and also disclosed the preparation of some related model compounds. ${ }^{1 \mathrm{c}, 9}$

Our synthesis of (-)-9 and (-)-10, patterned along a biomimetic route, emanated from (+)-7 and a modified and improved variant of our previously described synthesis of racemic $\mathbf{9}$ and $\mathbf{1 0}$ was executed. ${ }^{3}$ DIBAL-H reduction of $(+)-7$ was regio- and stereoselective ${ }^{10}$ and directed by the primary hydroxyl group and epoxide oxygen and furnished diol (-)-12 through the intermediacy of the aluminium chelate 11, Scheme $3 .{ }^{11}$ The diol moiety in 12 was protected as the acetonide (-)-13. Reduction of the carbonyl group in $\mathbf{1 3}$ with Luche reagent ${ }^{12}$ was moderately stereoselective, directed through the coordination of the ceric ion with the epoxy oxygen, to furnish a 7:1 diastereomeric mixture, which on further acetate hydrolysis led to (-)-14 and (-)-15. The relative stereochemical issue was settled through the $\mathrm{X}$-ray crystal structure determination ${ }^{13}$ of the minor diastereomer (-)-14, Scheme $3 .^{11}$ The primary hydroxyl group in the major epimer (-)-15 was chemoselectively oxidized with TEMPO $^{14}$ to furnish the aldehyde (-)16. $^{11}$

Although hydroxy-aldehyde (-)-16 was ready for the installation of the requisite side chain, we found that without the protection of the hydroxyl group, Wittig olefination was capricious. Protection of the hydroxyl group as acetate 17a and Wittig olefination furnished a 1:1 mixture of $E$ and $Z$ isomers $18 a$ in moderate yield. Protection of the hydroxyl group in $\mathbf{1 6}$ as TES ether $\mathbf{1 7 b}$ and Wittig olefination gave 18b in improved yield and an altered $E: Z$ ratio of $1: 3$, Scheme 4 . For further efforts, both 18a and 18b were serviceable and after hydroxyl group deprotection and oxidation, diastereomeric $(E)$ dienone (-)-19 and (Z)-dienone (-)-20 were readily separated and fully characterized, Scheme $4 .{ }^{11}$

The acetonide deprotection in (-)-19 and (-)-20 led to the diols (-)-21 and (-)-22, respectively, Scheme 5.11 TEMPO mediated ${ }^{14}$ chemoselective oxidation of (-)-21 and (-)-22 furnished aldehydes $\mathbf{2 3}$ and $\mathbf{2 4}$, respectively, to set up the pericyclic cascade of $6 \pi$ electrocyclization 
<smiles>CC1CCCCC1CO</smiles>

(+) -7

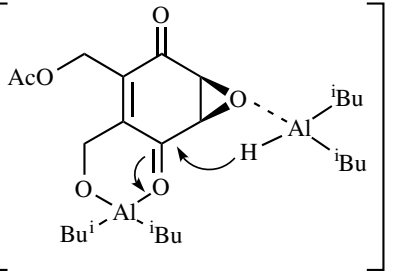

11<smiles>C[14CH2]OCC1=C(CO)[C@H](O)C2OC2C1=O</smiles>

(-) -12<smiles>C[13CH2][14CH2]OCC1=C2COC(C)(C)O[C@H]2[C@H]2OC2C1=O</smiles>

(-) -13<smiles>CC1(C)OCC2=C(C=O)[C@H](O)C3OC3[C@H]2O1</smiles>

$(-)-16$

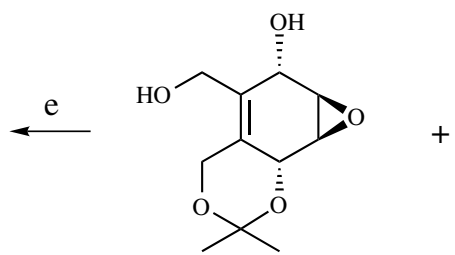

(-) - 15<smiles>CC1(C)OCC2=C(CO)[C@H](O)C3OC3[C@@H]2O1</smiles>

(-) -14

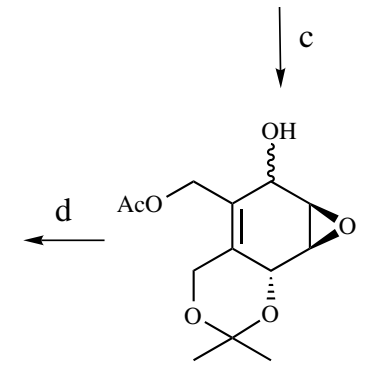

$\alpha: \beta=7: 1$

Scheme 3. Reagents and conditions: (a) DIBAL-H, THF, $-78^{\circ} \mathrm{C}, 74 \%$; (b) DMP, PPTS, acetone, $\mathrm{rt} 89 \%$; (c) $\mathrm{NaBH}_{4}, \mathrm{CeCl}_{3} \cdot 7 \mathrm{H}_{2} \mathrm{O}, \mathrm{MeOH}^{\circ}{ }^{\circ} \mathrm{C}$, $86 \%$; (d) $\mathrm{K}_{2} \mathrm{CO}_{3}, \mathrm{MeOH}, 0{ }^{\circ} \mathrm{C},(-)-14(11 \%)$ and (-)-15 (74\%); (e) TEMPO, $\mathrm{O}_{2}, \mathrm{CuCl}, \mathrm{DMF}, 76 \%$.<smiles>C/C=C/C1=C2COC(C)(C)O[C@H]2C2CC2[C@@H]1Oc1ccccc1</smiles>
$(-)-16$
$(-)-17 \mathbf{a}: \mathrm{R}=\mathrm{Ac}$
18a : R= Ac, $E: Z(1: 1)$

(-)-17b : R= TES

18b : R= TES, $E: Z(1: 3)$<smiles>C/C=C\C1=C2COC(C)(C)O[C@@H]2[C@@H]2O[C@H]2C(=O)C(/C=C/C)=C1C(C)(F)C(C)C</smiles>

$(-)-19$

(-) - 20

Scheme 4. Reagents and conditions: (a) $\mathrm{Ac}_{2} \mathrm{O}$, pyridine, DMAP, DCM, $0{ }^{\circ} \mathrm{C}, 87 \%$; (b) TESCl, imidazole, DMAP, DCM, $0{ }^{\circ} \mathrm{C}, 70 \%$; (c) $\mathrm{C}_{2} \mathrm{H}_{5} \mathrm{PPh}_{3} \mathrm{Br}, n$-BuLi, THF, $0{ }^{\circ} \mathrm{C}\left(52 \%\right.$ for 18a, $76 \%$ for 18 b); (d) $\mathrm{K}_{2} \mathrm{CO}_{3}, \mathrm{MeOH}, 0{ }^{\circ} \mathrm{C}, 90 \%$; (e) HF.py, THF, $0{ }^{\circ} \mathrm{C}, 78 \%$; (f) $\mathrm{PDC}, \mathrm{DCM}, 0{ }^{\circ} \mathrm{C}, 81 \%$.

and [4+2]-cycloaddition as depicted in Scheme 5. When aldehydes $\mathbf{2 3}$ and $\mathbf{2 4}$ were left aside neat at ambient temperature, the desired cyclization-cycloaddition occurred readily. In the $(E)$-series (-)-epoxyquinols (-)9 and $(-)-\mathbf{1 0}$ were obtained in a ratio of 3.5:1 from 21, Scheme 5. On the other hand, in the $(Z)$-series $(-)$ epoxyquinols (-)-9 and (-)-10 were realized in a ratio of 4:1 in comparable yield. ${ }^{15}$ While an hetero-[4+2]cycloaddition through an endo-transition state $\mathbf{2 5}$ accounts for the formation of (-)-9, an analogous homo-[4+2] cycloaddition through an exo-transition state would result in the formation of (-)-10. It is interesting to note that both the diastereomers (-)-21 and (-)-22 are serviceable and undergo the projected electrocyclizationcycloaddition cascade process with equal felicity and efficiency to furnish the epoxyquinol natural products.

In short, we have outlined a simple, convenient access to enantiomerically enriched, versatile building blocks $(+)-7$ and (-)-7 from the readily available Diels-Alder adduct of cyclopentadiene and $p$-benzoquinone. The former has been elaborated to (-)-epoxyquinols A 9 and B 10, following a biomimetic pathway. 


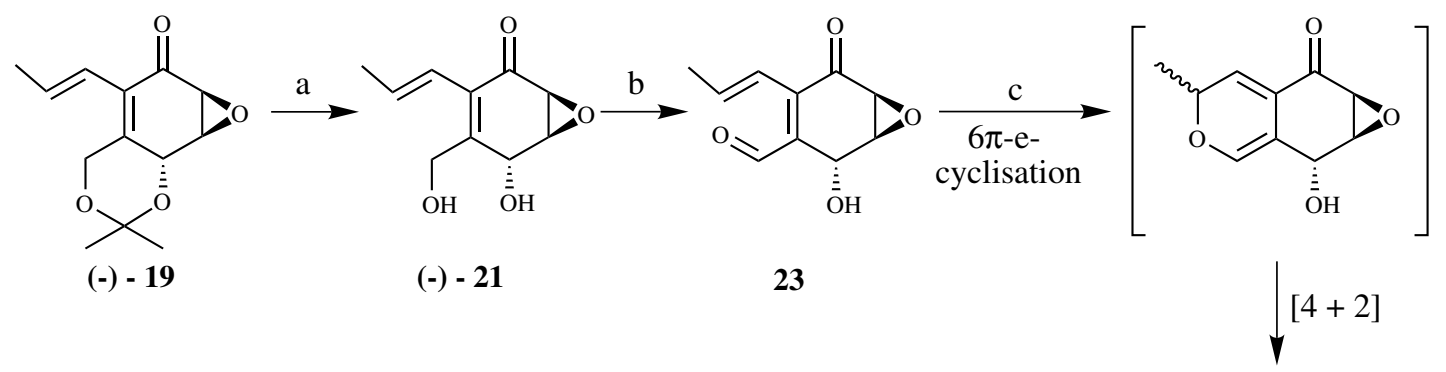

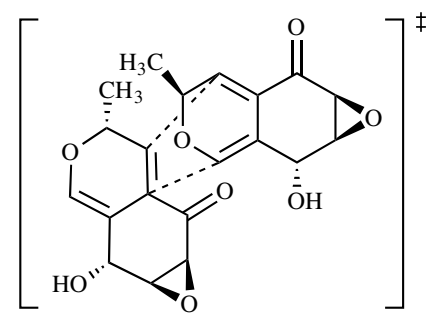

25

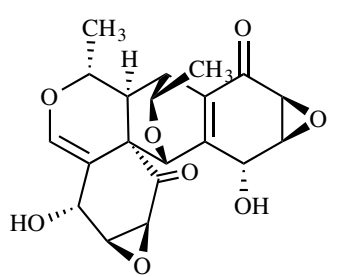

$(-)-9$

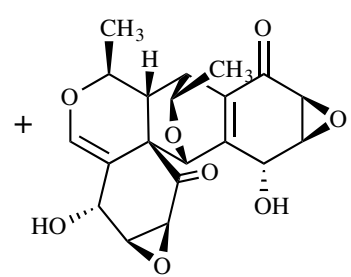

$(-)-10$

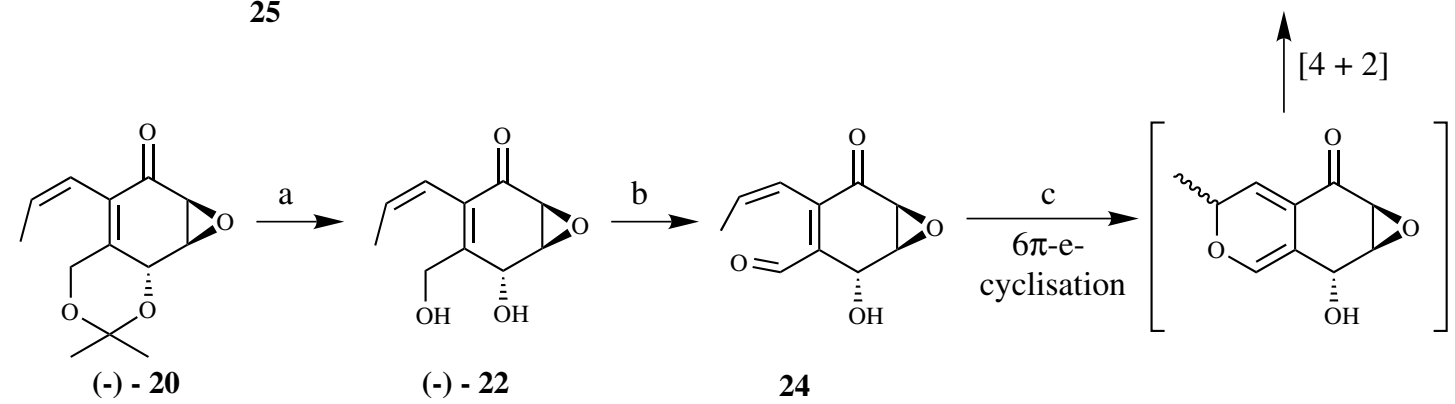

Scheme 5. Reagents and conditions: (a) Amberlyst 15, $\mathrm{MeOH}, \mathrm{rt}$ (79\% for 21, 73\% for 22); (b) TEMPO, $\mathrm{O}_{2}, \mathrm{CuCl}, \mathrm{DMF}, \mathrm{rt}$; (c) neat, $\sim 30{ }^{\circ} \mathrm{C}, 8 \mathrm{~h}$, $(-)-9(48 \%)$ and $(-)-10(18 \%)$.

\section{Acknowledgements}

K.I. thanks CSIR, India for the award of a research fellowship. This work was supported by the Chemical Biology Unit of JNCASR at the Indian Institute of Science, Bangalore. The lipase used in this study was a gift from Dr. Y. Hirose of Amano Pharmaceutical Co. Ltd, Japan.

\section{References and notes}

1. (a) Eupenoxide: Duke, R. K.; Rickards, R. W. J. Org. Chem. 1984, 49, 1898; Liu, Z.; Jensen, P. R.; Fenical, W. Phytochemistry 2003, 64, 571; (b) Cycloepoxydon: Gehrt, A.; Erkel, G.; Anke, H.; Anke, T.; Sterner, O. Nat. Prod. Lett. 1997, 9, 259; Gehrt, A.; Erkel, G.; Anke, T.; Sterner, O. J. Antibiot. 1998, 51, 455; (c) ECH: Kakeya, H.; Miyake, Y.; Shoji, M.; Kishida, S.; Hayashi, Y.; Kataoka, T.; Osada, H. Bioorg. Med. Chem. Lett. 2003, 13, 3743.

2. Selected references: (a) Kamikubo, T.; Ogaswara, K. Chem. Commun. 1996, 1679; (b) Kamikubo, T.; Hiroya, K.; Ogaswara, K. Tetrahedron Lett. 1996, 37, 499; (c) Taylor, R. J. K.; Alkaraz, L.; Kapfer-Eyer, I.; Macdonald, G.; Wei, X.; Lewis, N. Synthesis 1998, 775; (d) Li, C.; Lobskovsky, E.; Porco, J. A., Jr. J. Am. Chem. Soc. 2000, 122, 10484; (e) Wood, J. L.; Thompson, B. D.; Yusuff, N.; Pflum, D. A.; Matthaus, S. P. J. Am. Chem. Soc. 2001, 123, 2097; (f) Genski, T.; Taylor, R. J. K. Tetrahedron
Lett. 2002, 43, 3573; (g) Lei, X.; Johnson, R. P.; Porco, J. A., Jr. Angew. Chem., Int. Ed. 2003, 42, 3913; (h) Mehta, G.; Ramesh, S. S. Tetrahedron Lett. 2004, 45, 1985; (i) Mehta, G.; Islam, K. Org. Lett. 2004, 6, 807.

3. Mehta, G.; Islam, K. Tetrahedron Lett. 2003, 44, 3569.

4. (a) Kakeya, H.; Onose, R.; Koshino, H.; Yoshida, A.; Kobayashi, K.; Kageyama, S.-I.; Osada, H. J. Am. Chem. Soc. 2002, 124, 3496; (b) Kakeya, H.; Onose, R.; Yoshida, A.; Koshino, H.; Osada, H. J. Antibiot. 2002, 55, 829.

5. Enantiomeric excess (ee) was determined through ${ }^{1} \mathrm{H}$ NMR analyses (integration of the acetate methyl groups) after the addition of chiral shift reagent tris[3-(trifluoromethylhydroxymethylene)-(+)-camphorato]europium (III). Procedure for enzymatic transesterification: A mixture of meso-diol $\mathbf{5}(2 \mathrm{~g}, 10.9 \mathrm{mmol})$, vinyl acetate $(4.09 \mathrm{~mL}, 43.6 \mathrm{mmol})$ and Amano lipase PS-30 immobilized on Celite $(2 \mathrm{~g})$ in $t$-butylmethylether was stirred for $6 \mathrm{~h}$ at $0{ }^{\circ} \mathrm{C}$. The reaction mixture was filtered through a pad of Celite and the filtrate was concentrated. The crude product was subjected to column chromatography on silica gel and elution with hexane/ethyl acetate (2:1) furnished $(+)-7(2.0 \mathrm{~g}, 82 \%)$ adjudged pure spectroscopically, as a colourless oil; $[\alpha]_{\mathrm{D}}^{24}+11.5$ (c 3.2, $\mathrm{CHCl}_{3}$ ). Procedure for enzymatic hydrolysis: A mixture of mesodiacetate 8 (50 mg, $0.187 \mathrm{mmol}$ ) and lipase from C. rugosa (Sigma-Aldrich) in distilled water $(1.5 \mathrm{~mL})$ was stirred at room temperature for $40 \mathrm{~h}$. The reaction mixture was kept neutral by occasional addition of phosphate buffer ( $\mathrm{pH} 7$ ). After the usual work-up involving extraction with ethyl acetate, the crude product was subjected to column chromatography on silica gel to furnish (-)-7 (28 mg, 
$86 \%$ based on recovered starting material) as a colourless oil; $[\alpha]_{\mathrm{D}}^{24}-11.6\left(c\right.$ 1.5, $\left.\mathrm{CHCl}_{3}\right)$.

6. (a) Ryan, C. J.; Wilding, G. Drugs Aging 2000, 17, 249; (b) Folkman, J.; Browder, T.; Palmblad, J. Thromb. Haemostasis 2001, 86, 23.

7. Paper, D. H. Planta Med. 1998, 64, 686.

8. (a) Shoji, M.; Yamaguchi, J.; Kakeya, H.; Osada, H.; Hayashi, Y. Angew. Chem., Int. Ed. 2002, 41, 3192; (b) Li, C.; Bardhan, S.; Pace, E. A.; Liang, M.-C.; Gilmore, T. D.; Porco, J. A. Org. Lett. 2002, 4, 3267.

9. (a) Shoji, M.; Kishida, S.; Takeda, M.; Kakeya, H.; Osada, H.; Hayashi, Y. Tetrahedron Lett. 2002, 43, 9155; (b) Shoji, M.; Kishida, S.; Kodera, U.; Shiina, I.; Kakeya, H.; Osada, H.; Hayashi, Y. Tetrahedron Lett. 2003, 44, 7205.

10. Kiyooka, S.-I.; Kuroda, H.; Shimasaki, Y. Tetrahedron Lett. 1986, 27, 3009.

11. All new compounds were characterized on the basis of spectral (IR, ${ }^{1} \mathrm{H}$ and ${ }^{13} \mathrm{C}$ NMR and mass spectral) data.

12. Gemal, A. L.; Luche, J. L. J. Am. Chem. Soc. 1981, 103, 5454.

13. X-ray data for (-)-14: X-ray data were collected at $293 \mathrm{~K}$ on a BRUKER SMART APEX CCD diffractometer with graphite monochromated MoK $\alpha$ radiation $(\lambda=$ $0.7107 \AA$ ). Structure was solved by direct methods (SIR92). Refinement was done by full-matrix least-squares procedures on $F^{2}$ using SHELXL-97. The nonhydrogen atoms were refined anisotropically whereas hydrogen atoms were refined isotropically. $\mathrm{C}_{11} \mathrm{H}_{16} \mathrm{O}_{5}, \mathrm{MW}=$ 228.24, colourless crystal, crystal system: monoclinic, space group: $C 2 / c$, cell parameters: $a=37.508$ (11) $\AA$, $b=6.415 \quad$ (2) $\AA, \quad c=9.288 \quad$ (2) $\AA, \quad \beta=92.690 \quad$ (5), $V=2245.2 \AA^{3}, Z=8, D_{\mathrm{c}}=1.35 \mathrm{~g} \mathrm{~cm}^{-3}, F(000)=976.0$, $\mu=0.11 \mathrm{~mm}^{-1}$. Total number of 1.s. parameters $=209$, $R 1=0.0436$ for $2028 F o>4 \sigma(F o)$ and 0.0534 for all 2452 data. $w R 2=0.1090, \mathrm{GOF}=1.011$, restrained $\mathrm{GOF}=$ 1.011 for all data (CCDC 234194). ORTEP diagram is shown below

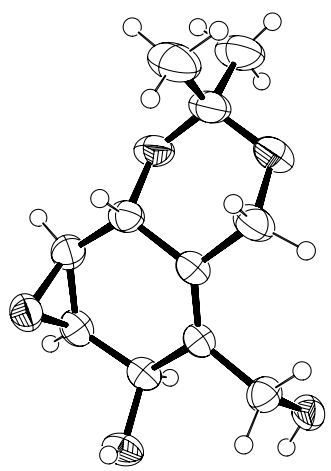

14. Semmelhack, M. F.; Schmid, C. R.; Cortes, D. A.; Chou, C. S. J. Am. Chem. Soc. 1984, 106, 3374.

15. Specific rotation for epoxyquinol A: $[\alpha]_{\mathrm{D}}(-)-58^{\circ}(c 0.43$, $\mathrm{MeOH})$, [lit. $\left.[\alpha]_{\mathrm{D}}(+)-61^{\circ}(c \quad 0.15, \mathrm{MeOH})\right]^{4 \mathrm{a}}$ and for epoxyquinol B: $[\alpha]_{\mathrm{D}}(-)-146^{\circ}(c 0.52, \mathrm{MeOH})$, $\left[\right.$ lit. $[\alpha]_{\mathrm{D}}(+)-$ $\left.153^{\circ}(c 0.32, \mathrm{MeOH})\right]^{4 \mathrm{~b}}$ 